\title{
Assessing User Engagement with a Fall Prevention Game as an Unsupervised Exercise Program for Older People
}

\author{
Jaime A. Garcia \\ Games Studio \\ University of Technology Sydney \\ Sydney, Australia \\ jaime.garcia@uts.edu.au
}

\author{
William L. Raffe \\ Games Studio \\ University of Technology Sydney \\ Sydney, Australia \\ william.raffe@uts.edu.au
}

\author{
Karla Felix Navarro \\ Faculty of Engineering and IT \\ University of Technology Sydney \\ Sydney, Australia \\ karla.felixnavarro@uts.edu.au
}

\begin{abstract}
Falling is, unfortunately, a leading cause of injury and death in the global elderly population. However, it has previously been shown that increased physical and cognitive activity can decrease the occurrence of falls in the elderly. This paper investigates the potential for a long-term, unsupervised fall prevention training tool in the form of the StepKinnection game, which was designed to exercise both reflex times and movement speed while also providing entertainment. Specifically, this game was used in a three month user study consisting of 10 participants over the age of 65 . Adherence to the training program, enjoyment of the game, and ease of use of the game were investigated using a custom usability questionnaire, four established usability scales, heuristic evaluation of gameplay data, and semi-structured interviews. Results show that participants generally had positive attitudes towards the game, they felt that they would engage with this training program more than there current exercises, and that the game was easy to use without guidance or supervision beyond the initial set up support and instructions provided at the start of the experiment period.
\end{abstract}

\section{KEYWORDS}

Fall prevention, elderly, older people, games for health, usability, engagement, Kinect

\section{INTRODUCTION}

With age, mental and physical health declines such that motor functions become often become impaired. This naturally increases the risk of developing health problems such as postural instability, balance disorders or simply having a fall. Due to this, falling is one of the leading causes of injury and fatality among the elderly [32], representing $2.55 \%$ of causes of death for Australians over the age of 85 , the highest cause of death by physical injury [22]. With the elderly population of Australia continuing to grow [21], this presents a wide spread national health concern.

One solution to this to encourage individuals to maintain mental and physical activity through exercise and social engagement to prevent health deterioration and improve motor skills that prevent falling or aid in reacting quickly to falling scenarios. Participating in a regular exercise program has been shown to be an effective intervention strategy with a $40 \%$ reduction in falls in user study participants [2]. However, continued compliance with an exercise program can be affected by motivation and it has been argued that motivation for physical activity in the elderly increases if the activity is enjoyable [13].

The entertainment provided by exertion games [19] available in the market has shown positive results in engaging the elderly in physical exercise and rehabilitation [12]. However, there are not many commercially available games that are specifically designed for an elderly audience, and even fewer that are designed to provide some form of therapeutic support for the player [20]. In a prior paper, the authors of the current paper presented the StepKinnection game [7], an interactive step training system designed for the elderly that combines:

(1) Appropriate age-related features to suit the needs and preferences of the elderly.

(2) Meaningful tasks and exercise routines that are aligned to this health problem.

(3) The collection stepping performance data to validate the effectiveness of the intervention.

The combination of these three aspects makes the game potentially useful as a training program as it (1) is appealing to and easy to use by an elderly audience, (2) trains specific physical and cognitive functions associated with falls, and (3) allows for a continuous assessment of health outcomes from gameplay data. It is predicted that the combination of these factors will make games such as this a viable long-term training solution. The focus of previous papers has been on verifying the second and third objective in this list; that is, verifying that the StepKinnection game does in fact improve mobility and balance in elderly participants, as measured through both in-game data and external clinical balance tests $[9,18]$. The data in [9] came from the same study presented in this paper and shows a significant increase in stepping and balance performance of the participants involved during the three month experimentation time period.

However, in order for the game to be appropriate for unsupervised training programs that span a long period of time, the game must be enjoyable enough for extended use as well as simple to use by an elderly audience with only minimal instruction from organizers and support staff. Therefore, the work presented in this paper evaluates the first of the earlier mentioned objectives by measuring the levels of adherence and compliance towards the StepKinnection game to determine whether it is feasible to use the game such as this as a long-term, home-based, unsupervised training tool for the elderly. This is done through a user study conducted over a three month period that examines data collected through a combination of a bespoke usability questionnaire, well known usability scales $[4,15,16,23]$, semi-structured interviews, and in-game metrics. It is important to note that there are many possible games that could be 
designed to achieve similar objectives and the authors do not claim that the StepKinnection game is the optimal solution. Rather, the primary contribution of this paper is to demonstrate an approach to empirically evaluating the usability and program adherence of fall prevention games.

The next section presents related work on preventing falls through physical activity. The StepKinnection game is then described in detail in Section 3, along with a discussion of the design choices made to encourage key physical movements. Section 4 presents the experimental methodology while Section 5 presents the results of the study in relation to usability and program adherence. Finally, a discussion of the implications of this work and potential future work are presented in Sections 6 and 7.

\section{STRATEGIES TO PREVENT FALLS}

Although falls are unpredictable, it is important to take action to reduce the likelihood of suffering falls. Physical activity and structured exercise have been shown to reduce the risk of developing several chronic diseases [5]. For the purpose of preventing falls, exercising has also been shown to be the most effective intervention [10]. Programs targeting the lower limbs have been demonstrated to improve several dimensions associated with falling such as gait speed and balance coordination [14]. In fact, interventions that did not include a walking component but involved balance exercises proved to reduce the risk of falling by $42 \%$ [27].

However, the effectiveness of such exercise interventions also relies on the level of exertion as well as intensity and duration of the activity that is being executed. For instance in the work done by Sherrington et al. [2008], it is suggested that exercises should challenge balance through the inclusion of tasks that involve moving the centre of mass, reducing the base of support and reducing the use of upper limbs to maintain a balanced position [27]. Howe et al. [2011] suggested that dynamic balance exercises should be conducted three times a week for 15 minutes in order to be effective [29].

Research by Yau et al. [2013] showed strength and power exercises were a good strategy to counterbalance the loss of muscle mass suffered as a consequence of ageing. Muscle mass decreases with age affecting muscle strength and power which subsequently affects postural stability [26]. Hence, training resistance can help to improve muscle strength [17], and conducting exercises at high speed with low intensity can improve muscular power [30].

In the work done by Draganski and May [2008] and Bhatt et al. [2012], stepping exercises involving a series of induced slips were shown to be an effective method for reducing falls in a laboratory setting. Similarly, in the work done by Studenski et al.[2010], step training showed improvements in dynamic balance and balance confidence, both associated with falling. Stepping requires the integration of several dimensions such as sensory, central and neuromuscular systems. By taking a short proactive or reactive step an individual can increase their base of support regaining balance. Hence, training this ability is important because it could be the last resort to prevent a fall from happening.
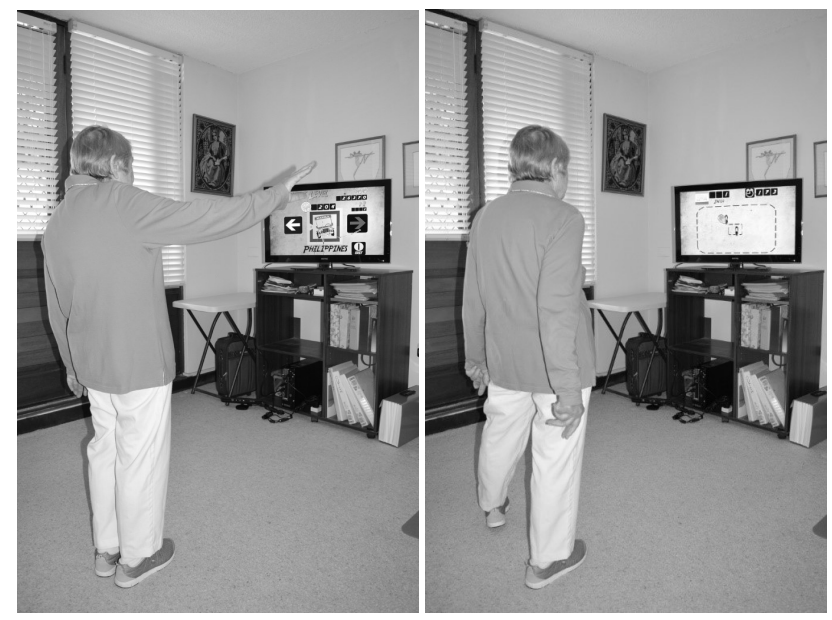

Figure 1: A participant interacting the main menu in StepKinnection (left) and playing one of the stepping tasks (right).

\section{THE STEPKINNECTION GAME}

In the StepKinnection game, the player is an explorer who travels around the globe visiting a wide range of countries, hunting for treasures and seeking different adventures [7]. The further they travel, the more the difficulty increases. Gameplay starts with a series of basic levels where players will have the chance to become familiar with the game and coordinate their movements accordingly. Once they have finished these levels, players can move up to more challenging ones related to speed, precision and cognitive complexity.

In order to play the game, the player needs to stand in front of the TV facing the Kinect, as shown in Figre 1. Shortly after, the main menu will be presented, where players can select from a list of counties to visit. The player can wave either hand to move the cursor to navigate the menu. Once the level is selected the user moves to the main stepping tasks.

\subsection{Stepping Tasks for Developing Motor Skills}

There are three main stepping tasks within the game, each designed to target a specific scenario and train the corresponding motor skills. These three activities include normal stepping, motor inhibition, and quick stepping.

For the normal stepping scenario, throughout the game fruits will appear in different areas of the screen every now and then, and the player is expected to collect them. In order to achieve this, the player needs to reach the fruits by stepping on them, with steps being registered by the Kinect sensor. As the user moves through the levels, the time between the appearance of the fruits and the size of the fruits decrease. This is to encourage players to perform quicker and more accurate steps as they advance to higher levels, representing an increase in both physical capability and game specific skills. This mechanism reinforces the ability to take proactive steps that could help an individual to regain balance and avoid falls. Also, as the stepping area decreases, the user needs to be more coordinated to be able to step on the fruits. 
In addition to this standard stepping routine, a motor inhibition task was incorporated with the purpose of adding varied difficulty to the game by slightly increasing the cognitive demand. According to Potocanac et al. [2014], adequate motor inhibition plays an important role in avoiding falls. Training this ability is therefore ideal for situations where avoiding an obstacle can prevent a fall from occurring. In the mid-levels, a lady bug might randomly appear on the screen. Stepping on the lady bug will take two penalty points off the current score, reducing the chances of winning. However, if the player remains in position, one point will be awarded.

Finally, in the higher levels, dollar coins randomly appear on the screen for a split-second. These coins are bonus points that can help players to move faster in the game, with the purpose of encouraging them to step faster. For each dollar coin that they collect, two bonus points will be added to their current score to reward the player. This feature trains the ability to respond quickly to a hazardous situation [24], such as circumstance where the person has initiated a step but the environment suddenly changes.

For all the above stepping tasks in the game, the accuracy of the responses is automatically processed by the hybrid clinical test for fall risk assessment that is embedded in the game $[8,18]$.

\section{EXPERIMENT METHODOLOGY}

A longitudinal study approach was selected in order to evaluate adherence to the training program over an extended period of time. For this study, all participants played with the StepKinnection game for 12 weeks. In order to determine whether it is feasible to use the game as a home-based training tool, a set of usability questionnaires were used after completing four weeks of intervention. Other clinical assessments were conducted at baseline and every four weeks in order to assess changes in the physical health and are reported in more detail in [9].

\subsection{Participants}

For this study, 12 participants aged $76.8 \pm 6.73$ years were recruited, with 10 residents from two retirement villages in Sydney and two independent-living older adults. However, two participants withdrew within the first month of the study, and so their data is not included in the results in Section 5. Eligibility was determined by the following inclusion criteria: be 65 years old (or older), live without professional assistance in the community, be able to walk independently without assistance, be fluent in the English language, own a flat screen TV (LCD, LED or Plasma) with a HDMI port, be able to watch TV from $3 m$ away (with or without their glasses), have enough room for system use $(1.2 m-2.5 m)$, and have no major cognitive impairments. Exclusion criteria were unstable health conditions, blindness or colour blindness, major cognitive impairments, inability to step unassisted and unable to walk independently. Written informed consent was obtained from all participants prior to their participation in this study.

\subsection{Experimental Set-up}

Participants were provided with the StepKinnection system which consists of a small computer, a Kinect sensor and a WiFi pocket modem (when required). The computer was attached to the participant's TV for the display of the game. The Kinect was connected to the computer for skeletal tracking purposes. Participants were encouraged to play as much as they wish. A minimum of three sessions of 20 minutes per week was recommended. Participants exercised in their own homes with no supervision. Instructions were given upon installation and an instruction booklet was provided for further reading. To encourage ongoing use, participants were contacted either by phone or face-to-face on a monthly basis.

\subsection{Data Collection}

A usability questionnaire was designed and administered to participants. This questionnaire consisted of twelve Likert items, each on a five point scale from "Strongly Disagree" to "Strongly Agree". The specific questions for this questionnaire can be seen in the results of Figure 2. An extra final question was asked, "Overall, I enjoyed using the game as a means to exercise", which was reported on a four point scale from "Disagree" to "Agree" in order to remove the neutral middle response.

Additionally, to assess enjoyment, adherence and the ease of use of the system, the following established scales were utilised:

- The ease of use and friendliness of the game as a system was assessed through the Systems Usability Scale (SUS) [4].

- Game specific usability and enjoyment was measured through the Play Experience Scale (PES) [23]

- The player's engagement with the game and state of flow were assessed through the Flow State Scale (FSS) [15].

- Attitude to physical activity was assessed through the Physical Activity Enjoyment Scale (PACES) [16].

Feelings towards the game not covered in the questionnaires, such as aspects that would make the game more enjoyable, difficulties experienced during the intervention and features that were not positively received, were assessed through a semi-structured interview. All questionnaires and interviews were conducted after the first 4 weeks (out of 12 total) to get early feedback on the game. This led to more levels being added to the game to encourage continued play throughout the remainder of the experiment. Meanwhile, compliance and adherence to the exercise intervention were assessed throughout the intervention period with the system logs.

To identify the participants' feelings and attitudes towards the StepKinnection game as a means to exercise at home, quantitative data obtained through the usability questionnaires were explored descriptively and graphically. For qualitative items obtained during the interviews, the answers were categorised to facilitate the presentation of the results.

\section{RESULTS}

This section presents the results of the study in regards to the custom designed usability questionnaire, the established questionnaires from the literature, the semi-structured interviews, and the in-game data collection. The implications of the results are further discussed in Section 6.

\subsection{Bespoke Usability Questionnaire}

The usability questionnaires revealed that the game was perceived as easy to use, playful and enjoyable (see Figure 2). Results showed that seven of the ten participants strongly agreed that they enjoyed 


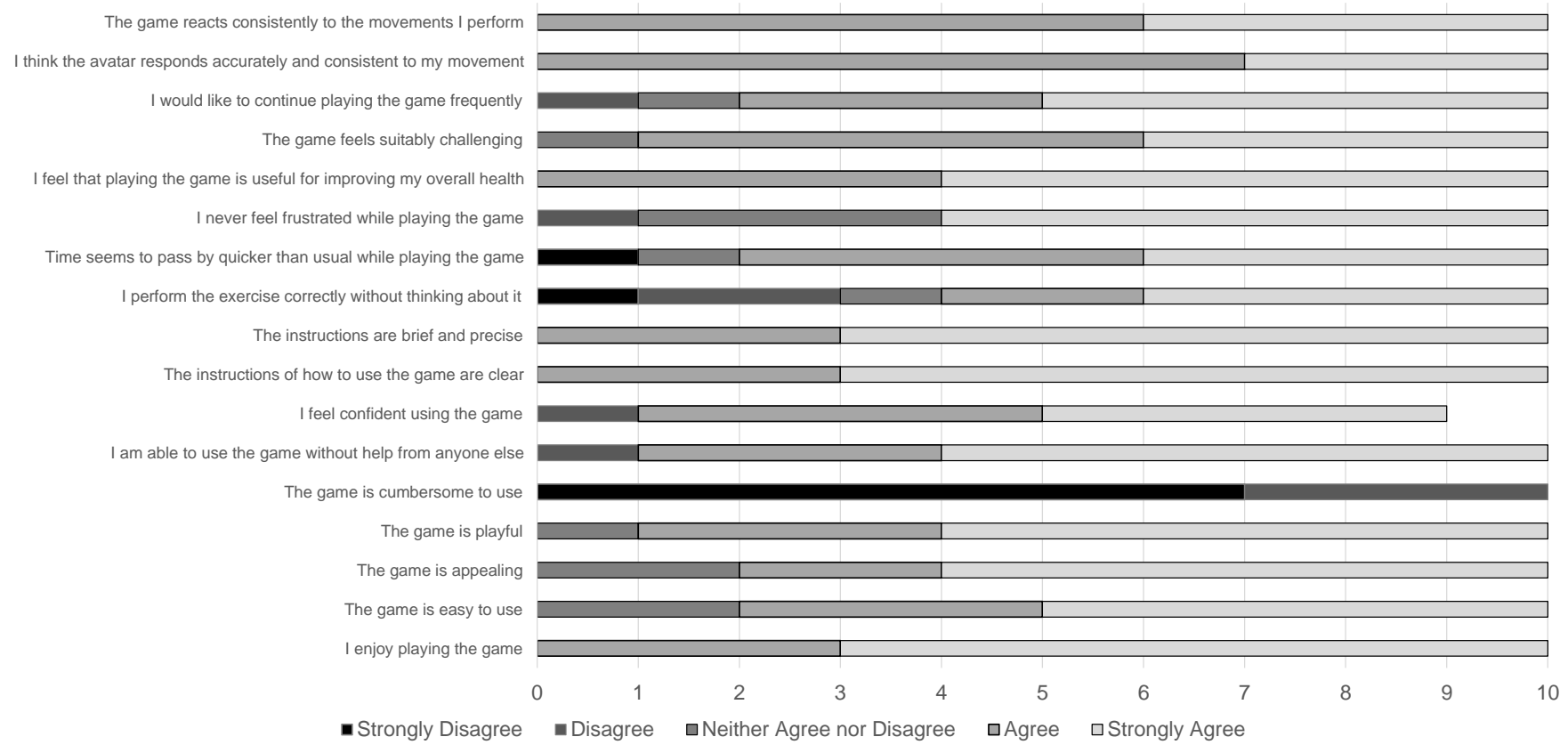

Figure 2: Results of the post experiment questionnaire for the 10 participants. One response was not submitted for the item "I feel confident using the game".

playing the game, and instructions on how to use the game were clear, brief and precise. When participants were questioned about their attitudes and feelings towards the game, six agreed that the game was appealing, the game was playful, and they were able to use the game without help from anyone else.

When asked if they felt that time seemed to alter while playing the game, nine participants responded favourably. In fact, four participants said that time seemed to pass by quicker than usual and six participants indicated that they performed the exercises without even thinking about it.

Regarding the accuracy of the controllers and the ability to interact with the game, seven of the participants strongly agreed that the game reacted consistently to the movements they performed. six participants stated that they thought the avatar responded accurately and consistently to their movements. The majority also answered favourably to questions concerning challenge or level of exertion. While nine of the participants agreed that the game felt suitably challenging, there was one participant who strongly disagreed.

On the potential benefits for mental and physical health, all participants expressed favourable opinions . They felt that playing the game was useful for improving their overall health (six strongly agreed, four agreed). Additionally, six participants also said they never felt frustrated while playing the game.

When asked if they would like to continue playing the game frequently, eight participants agreed with this statement, and the remaining two neither agreed nor disagreed. More importantly, when asked if they would consider using the system as a means to exercise, the majority responded positively: seven strongly agreed, one slightly agreed and two did not respond.

\subsection{Established Usability Questionnaires}

Table 1 presents descriptive statistics regarding the questions from the established scales that were most relevant to this evaluation. The SUS scale showed overwhelmingly that the users were able to use the system with confidence and would use it again, with a low standard deviation between participants. The PES scale, however, highlighted that that system sometimes did not respond as the participants wanted. This is likely due to technical glitches in the Kinect skeleton tracking making it hard at time to control the game, a sentiment that is reflected in the interviews presented in the next subsection.

The results of the FSS scale suggest that the participants enjoyed the game and the results of the PACES scale show that they appreciated the physical activity required to play the game. However, the lower mean and higher standard deviation of some of the key items in these two scales indicate that the not all of the participants entered a state of flow while playing the game. This suggests that improvements could be made in making the game more engaging for the elderly target audience, for which there is currently little well establish game design principles and research. It is expected that increasing the occurrence of a flow state would improve adherence to a game-based step training program.

\subsection{Semi-structured Interviews}

The semi-structured interview revealed other aspects that the questionnaires did not show. When asked about their experience with the game, all participants responded favourably. Several stated that it was very enjoyable and a 70 year old female even said "it was great, well researched, good for concentration and co-coordination”. 
Table 1: Descriptive statistics for the perceived ease of use and suitability of the game.

\begin{tabular}{|c|c|c|c|c|c|c|c|c|}
\hline & \multirow{2}{*}{\multicolumn{5}{|c|}{ Frequency }} & \\
\hline & & & & & & & & \\
\hline Scale & Item & $\begin{array}{l}\text { Strongly } \\
\text { Disagree }\end{array}$ & Disagree & Neutral & Agree & $\begin{array}{l}\text { Strongly } \\
\text { Agree }\end{array}$ & Mean & SD \\
\hline \multirow{3}{*}{$\begin{array}{l}\text { Usability of the System } \\
\text { (SUS) } \\
\text { 1-to-5 rating scale, where } \\
\text { 5: Strongly Agree. }\end{array}$} & I felt very confident using the system & 0 & 0 & 1 & 2 & 7 & 4.6 & 0.66 \\
\hline & $\begin{array}{l}\text { I think that I would like to use this system } \\
\text { frequently }\end{array}$ & 0 & 1 & 0 & 3 & 6 & 4.4 & 0.92 \\
\hline & I thought the system was easy to use & 0 & 0 & 0 & 4 & 6 & 4.6 & 0.49 \\
\hline \multirow{2}{*}{$\begin{array}{l}\text { Play Experience Scale } \\
\text { (PES) } \\
\text { 1-to-5 rating scale, where } \\
\text { 5: Strongly Agree. }\end{array}$} & $\begin{array}{l}\text { I was able to make the game do what I } \\
\text { wanted it to }\end{array}$ & 1 & 3 & 2 & 2 & 2 & 3.1 & 1.3 \\
\hline & $\begin{array}{l}\text { I am able to use the game without help } \\
\text { from anyone else }\end{array}$ & 0 & 1 & 0 & 3 & 6 & 4.4 & 0.92 \\
\hline \multirow{7}{*}{$\begin{array}{l}\text { Flow State Scale } \\
\text { (FSS) } \\
\text { 1-to-5 rating scale, where } \\
\text { 5: Strongly Agree. }\end{array}$} & $\begin{array}{l}\text { I felt I was competent enough to meet } \\
\text { the high demands of the situation }\end{array}$ & 0 & 1 & 0 & 4 & 5 & 4.3 & 0.9 \\
\hline & $\begin{array}{l}\text { I made the correct movements without } \\
\text { thinking about trying to do so }\end{array}$ & 0 & 1 & 2 & 3 & 4 & 4 & 1 \\
\hline & It felt like time went by quickly & 1 & 0 & 1 & 5 & 3 & 3.9 & 1.14 \\
\hline & I really enjoyed the experience & 0 & 0 & 1 & 2 & 6 & 4.56 & 0.68 \\
\hline & $\begin{array}{l}\text { I loved the feeling of the performance } \\
\text { and want to capture it again }\end{array}$ & 0 & 0 & 2 & 5 & 3 & 4.1 & 0.7 \\
\hline & My goals were clearly defined & 0 & 0 & 1 & 4 & 5 & 4.4 & 0.66 \\
\hline & I knew clearly what I wanted to do & 0 & 0 & 3 & 2 & 5 & 4.2 & 0.87 \\
\hline \multirow{5}{*}{$\begin{array}{l}\text { Physical Activity } \\
\text { Enjoyment Scale (PACES) } \\
\text { 1-to-10 rating scale, where } \\
10 \text { and 9: Strongly Agree. }\end{array}$} & $\begin{array}{l}\text { I felt as though there was nothing else I } \\
\text { would rather be doing }\end{array}$ & 2 & 0 & 0 & 2 & 5 & 7.33 & 3.27 \\
\hline & $\begin{array}{l}\text { I enjoyed using the game as a means to } \\
\text { exercise }\end{array}$ & 2 & 0 & 0 & 1 & 7 & 7.12 & 0.33 \\
\hline & I am very absorbed in this activity & 2 & 0 & 0 & 2 & 5 & 7.33 & 3.53 \\
\hline & I am not at all frustrated by it (the game) & 0 & 1 & 1 & 1 & 5 & 8.38 & 2.34 \\
\hline & I feel good physically while doing it & 1 & 0 & 0 & 2 & 5 & 8.25 & 2.95 \\
\hline
\end{tabular}

When they were questioned about the characteristics they like about the game, four people stated that they "liked the challenges". A male participant said he liked that the game "was simple and consistent", and a 69 year old female stated that it is a game to "exercise your legs and brain attention with info from the countries you visit”.

Questions regarding aspects that participants dislike showed some opposite opinions. While a 79 year old male expressed that he "had to be alert and ready to focus", and a 69 year old man said the games "don't always hold [his] concentration". Also, two people mentioned that in some cases "the gold coins [reward] would disappear too quickly from the screen, so [their] step would not count".

Regarding the existence of problems such as technical difficulties or game glitches, three participants indicated that they had trouble getting the avatar to move. Apparently, the Kinect sensor was not able to detect them. It is likely that the sensor was not recognised by the computer during the start sequence or perhaps inadequate lighting conditions or loose clothing could have affected the skeletal recognition. However, participants indicated that the problem was quickly resolved by restarting their computers.

When asked about the challenge of the workouts, most of the participants stated that the game was suitable for their abilities, and one subject even said "a good challenge to concentrate and move quickly”. However, two female participants (aged 83 and 81 years) responded quite differently. While one thought the game was "quite challenging", the other said that she found it "fairly easy".

Questions regarding changes that could potentially improve the game showed a favourable trend. Six of the participants stated that they would not modify the game. There were however two participants (a male aged 79 and a female aged 67) who suggested changes in the speed in which stimuli appear on the screen. For example a female participant said she "would make the first levels a little faster". In addition to this, a 69 year old male suggested that the ability to "play music of their preference would make the game 


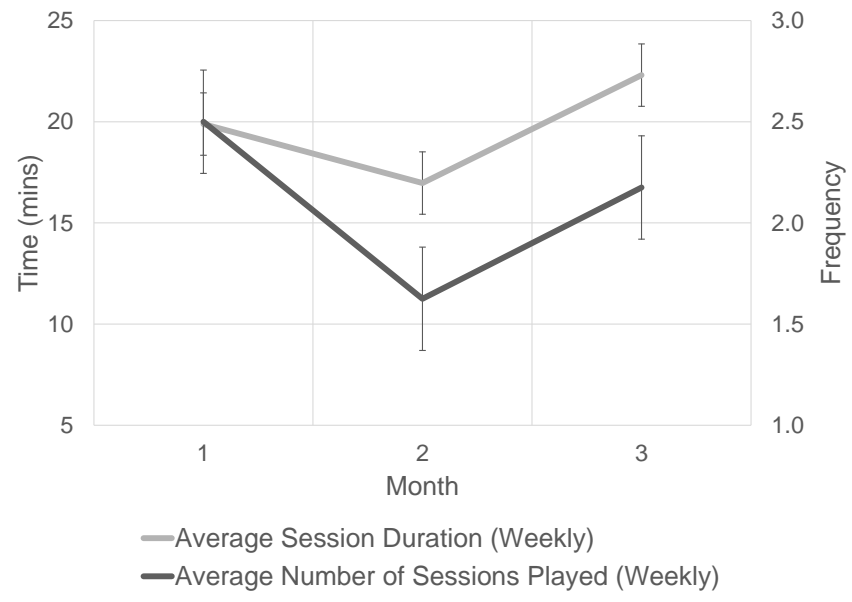

Figure 3: Participants' adherence throughout the 12 week intervention.

more enjoyable". Also, an 83 year old female proposed the inclusion of more levels within the game in order to make it more interesting.

When asked if the game would motivate them to do their exercises, there were encouraging responses. Eight of the participants indicated that the game would motivate them more than usual exercises. The remaining two participants said that their motivation towards physical activity would be about the same as performing usual exercises.

Finally, when asked if they would like to use the game as a means to exercise, eight of the ten participants answered positively. One female even said "it is quite different to the usual type of exercise we are given". Another female stated that she "would like to keep using the game to ensure [she] keeps moving [her] body". Also, there were some interesting perspectives and attitudes towards the game. While a 69 year old male expressed that he "preferred outdoor activities" rather than playing a game in his living room, an 83 year old female who prefers to "exercise in isolation" said that she likes the game because it allows her to exercise in the comfort of her home.

\subsection{Program Adherence}

Regarding adherence to and progression through the program, system logs indicated that all the participants used the step training system throughout the 12 week intervention period. However, the frequency of use and amount of time spent on the system varied over time.

As shown in Figure 3, in the first month there were high levels of adherence with an average of 2.5 sessions per week and a mean duration of 20 minutes per session. In the second month, there was a reduction in the frequency of use to 1.6 sessions per week and a decrease in the average session duration from 20 minutes to 16.9 minutes. Finally, in the third month there was an increase in the levels of motivation where the number of sessions played increased from 1.6 to 2.2 sessions per week and the amount of time spent per session increased from 16.9 minutes to 22.3 minutes. The drop in engagement in the second month is primarily due to two factors.
First, a few of the participants had other events in their life at that time, such as going on vacation or having surgery, meaning that they did not have access to game, indicting that such a training program may be more beneficial if it could be made more portable. Secondly, by this time most participants had completed all of the levels initially supplied with the game, and the repetition of playing the same levels caused some participants to become disengaged. By the third month, the number of levels available in the game was doubled and so these participants recommenced their training. This highlights that using a game as an exercise program for the elderly requires enough levels or variety of gameplay to last the entirety of the program duration.

Looking at the individual usage of participants shown in Table 2 , at the end of the intervention in week 12, two participants had spent a total of 15.2 to 15.3 hours playing with the game, three had played 9.9 to 11.8 hours, three had played between 5 hours and 6.4 hours, and the remaining two had played less than 2 hours each. The participant who spent the most time on the game played a total of 15.5 hours in 25 sessions, and the participant who reported the highest frequency of use played 68 sessions in 15.2 hours.

Regarding progress within the game, Table 2 also showes that at the end of the first week, two participants were playing at the easy levels (Level 0 and 1), six were at the medium difficulty levels (Levels 6-9) and two were at the highest level available (Level 15). In contrast, at the end of the intervention in week 12 after more levels were added due to the questionnaire feedback at the end of the first month, seven of the participants reached the highest level (Level 31), one person was playing at the hard levels (Level 16) and the remaining two were still at the medium levels (Level 4 and 8).

\section{DISCUSSION}

Based on the results, the questionnaires showed that the participants had positive attitudes and feelings towards the StepKinnection game. Similarly to the initial usability assessments conducted prior to this intervention to validate core aspects of the game design [7], the acceptance of the game was favourable. Overall, participants found the game pleasant, easy to use and enjoyable.

As an indication of the improved usability by iterative usercentred game design, the previous study identified a series of issues related to the use of the main menus in the StepKinnection game [7]. This generated feelings of dissatisfaction among participants who were unable to make the game do what they wanted to. While the results of the PES scale suggest that some issues may still be present, they are much reduced here.

In regards to the level of exertion and challenge, the cognitive demanding activities and the ability to adapt the step length to the user height seemed to suit the user abilities. Since the game aims to improve certain motor and cognitive functions associated with falling, these tasks need be aligned to train coordination, muscle strength, attention, motor inhibition and the ability to respond quickly to hazardous situations. The game challenge was determined by the incorporation of tasks that were aligned to the problem of preventing falls, not just by increasing the number of obstacles in a linear way.

Although there were two drop-outs before starting the intervention, the ten participants who completed the 12 week program 
Table 2: Descriptive indicators of adherence and progression.

\begin{tabular}{|c||c|c|c|c|c|c|c|c|}
\hline & $\begin{array}{c}\text { Total Time } \\
\text { Spent } \\
\text { (Hours) }\end{array}$ & $\begin{array}{c}\text { Total } \\
\text { Sessions } \\
\text { Payed }\end{array}$ & $\begin{array}{c}\text { Average } \\
\text { Time Spent } \\
\text { Weekly } \\
\text { (mins) }\end{array}$ & $\begin{array}{c}\text { Average } \\
\text { Sessions } \\
\text { Played per } \\
\text { Week }\end{array}$ & $\begin{array}{c}\text { Mean } \\
\text { Session } \\
\text { Duration } \\
\text { (mins) }\end{array}$ & $\begin{array}{c}\text { Number of } \\
\text { Session at } \\
\text { End of } \\
\text { Week 1 }\end{array}$ & $\begin{array}{c}\text { Max Level } \\
\text { Reached at } \\
\text { End of } \\
\text { Week 1 }\end{array}$ & $\begin{array}{c}\text { Max Level } \\
\text { Reached at } \\
\text { End of } \\
\text { Week 12 }\end{array}$ \\
\hline \hline 1 & 9.9 & 35 & 37.1 & 2.2 & 17 & 5 & 7 & 31 \\
\hline 2 & 1.7 & 12 & 6.3 & 0.8 & 8.4 & 3 & 1 & 4 \\
\hline 3 & 15.2 & 68 & 57 & 4.3 & 13.4 & 7 & 9 & 31 \\
\hline 4 & 5 & 19 & 18.8 & 1.2 & 15.8 & 6 & 9 & 16 \\
\hline 5 & 6.4 & 17 & 24.1 & 1.1 & 22.7 & 5 & 9 & 31 \\
\hline 6 & 5.9 & 28 & 22 & 1.8 & 12.6 & 6 & 6 & 25 \\
\hline 7 & 1.5 & 6 & 5.7 & 0.4 & 15.1 & 1 & 0 & 8 \\
\hline 8 & 10 & 15 & 37.5 & 0.9 & 40 & 5 & 15 & 31 \\
\hline 9 & 15.5 & 25 & 58.2 & 1.6 & 37.2 & 7 & 15 & 31 \\
\hline 10 & 11.8 & 27 & 44.3 & 1.7 & 26.2 & 3 & 6 & 31 \\
\hline
\end{tabular}

showed good levels of adherence and motivation throughout the study. According to the academic literature, the ability to train at home increases seniors' adherence to physical exercise in the longterm [1]. Also, there is evidence that suggests that home-based exercises are effective in reducing the risk of falling in older people [11] . Consequently, the high adherence rates and the increase in stepping performance and health benefits found during the study period [9] suggest that the use of StepKinnection in the long-term may be effective as a tool to reduce the risk of falling in the elderly.

The StepKinnection game was also demonstrated to be feasible to administer and easy to use. All the participants recruited for this study were able to play the game, navigate through the menus, change levels of difficulty, and perform the stepping routines with only initial instruction for the investigators. The ten participants also indicated that they enjoyed the stepping training and found it useful to improve their health. However, the game design could also be improved to further engage elderly players by increasing the chance of entering a state of flow, which would further increase motivation and adherence to the training program. In regards to the cognitive tasks added to stimulate specific functions related to the risk of falling, participants found the lady bug and the coins to game elements. More importantly, no adverse events related to the intervention were reported. This suggests that the StepKinnection game is a safe mode of exercise for higher functioning older adults and can be used without supervision in the comfort of their home.

One of the main limitations of this study is the small sample size that made it difficult to generalise some of our findings. For example, there was a 93 year old participant who withdrew from the study after one week of intervention. She stated that she was unable to progress within the game levels and found it difficult to remember how to use certain features of the game. This suggests that the system might not be suitable for people with mild cognitive impairments. Additionally, due to complications during the intended recruitment of more participants for this study, it was not possible to set up and monitor a control group for comparisons pre and post intervention. Despite this, the findings are still considered relevant and meaningful as the outcome measures presented high levels of enjoyment, adherence and acceptance.

\section{CONCLUSIONS}

This study presents the results of a 12 week intervention that evaluates adherence, enjoyment and the ease of use of the StepKinnection game in order to determine its suitability for use as an unsupervised home-based training tool for the elderly. This pilot study found that long-term training over 12 weeks with the Kinect-based stepping game was safe and feasible to administer in the home in an unsupervised manner and maintained interest over the course of the intervention.

The fun factor in video games is the key to keep people motivated and engaged with the desired activity. Simple tasks and clearly defined goals have been shown to be most effective when designing video games for this specific audience. However, feelings of frustration may rise when interfaces or game procedures are not simple enough. Older people with no computer literacy may develop feelings of confusion when interacting with interfaces that present too many options. Frustration and annoyance often cause of demotivation and player churn in physical training programs [13]. For that reason, it is highly recommended to apply user-centred design methodologies such as the heuristic evaluations of interfaces [18] and the well established usability and flow scales. These inspection techniques can be helpful in identifying hidden usability issues of interfaces and improving engagement.

Future work involves further investigating game design for older people, especially in the sense of encouraging physical activity. This is a under represented target audience both within commercial game development and research and so more work is needed to properly understand the design principles that relate to this audience and that are likely to encourage flow experiences. Additionally, there are opportunities for this type of step training to not only improve physical health but also mental health. Anecdotally, one participant commented on that the music in the game produced 
positive thoughts of the various countries that the music was designed to represent. This suggests that a game could be designed to provide relief for depression suffers as well as reducing the risk of falling.

\section{ACKNOWLEDGMENTS}

This research was approved by the University of New South Wales Human Research Ethics Committee (UNSW HREC HC12316) and ratified by the University of Technology Sydney Human Research Ethics Committee (UTS HREC 2012-279R).

\section{REFERENCES}

[1] Nigel L Ashworth, Karen E Chad, Elizabeth L Harrison, Bruce A Reeder, and Shawn C Marshall. 2005. Home versus center based physical activity programs in older adults. The Cochrane Library (2005).

[2] Anne Barnett, Ben Smith, Stephen R Lord, Mandy Williams, and Adrian Baumand. 2003. Community-based group exercise improves balance and reduces falls in at-risk older people: a randomised controlled trial. Age and ageing 32, 4 (2003), 407-414.

[3] Tanvi Bhatt, Feng Yang, and Yi-Chung Pai. 2012. Learning to resist gait-slip falls long-term retention in community-dwelling older adults. Archives of physical medicine and rehabilitation 93, 4 (2012), 557-564.

[4] John Brooke et al. 1996. SUS-A quick and dirty usability scale. Usability evaluation in industry 189, 194 (1996), 4-7.

[5] Wojtek J. Chodzko-Zajko, David N. Proctor, Maria A. Fiatarone Singh, Christopher T. Minson, Claudio R. Nigg, George J. Salem, and James S. Skinner. 2009. American College of Sports Medicine position stand. Exercise and physical activity for older adults. Med Sci Sports Exerc 41, 7 (2009), 1510-30. https: //doi.org/10.1249/MSS.0b013e3181a0c95c

[6] Bogdam Draganski and Arne May. 2008. Training-induced structural changes in the adult human brain. Behavioural brain research 192, 1 (2008), 137-142.

[7] Jaime A Garcia and Karla Felix Navarro. 2015. StepKinnection: a fall prevention game mindfully designed for the elderly. Studies in health technology and informatics 214 (2015), 43-49.

[8] Jaime Andres Garcia, Yusuf Pisan, Chek Tien Tan, and Karla Felix Navarro. 2014 Step kinnection: a hybrid clinical test for fall risk assessment in older adults. In CHI'14 Extended Abstracts on Human Factors in Computing Systems. ACM, 471-474.

[9] Jaime A Garcia, Daniel Schoene, Stephen R Lord, Kim Delbaere, Trinidad Valenzuela, and Karla Felix Navarro. 2016. A bespoke Kinect stepping exergame for improving physical and cognitive function in older people: A pilot study. Games for health journal 5, 6 (2016), 382-388.

[10] Lesley D Gillespie, M Clare Robertson, William J Gillespie, Sarah E Lamb, Simon Gates, Robert G Cumming, and Brian H Rowe. 2009. Interventions for preventing falls in older people living in the community. Cochrane Database Syst Rev. 2 (2009), CD007146.

[11] Lesley D Gillespie, M Clare Robertson, William J Gillespie, Catherine Sherrington, Simon Gates, Lindy M Clemson, and Sarah E Lamb. 2012. Interventions for preventing falls in older people living in the community. The Cochrane Library (2012).

[12] Sylvain Hanneton et al. 2009. Coaching the Wii. In Haptic Audio visual Environments and Games, 2009. HAVE 2009. IEEE International Workshop on. IEEE, 54-57.

[13] Dorte Høst, Carsten Hendriksen, and Ina Borup. 2011. Older peopleâĂŹs perception of and coping with falling, and their motivation for fall-prevention programmes. Scandinavian fournal of Social Medicine 39, 7 (2011), 742-748.

[14] Tracey Howe, Lynn Rochester, Fiona Neil, Dawn Skelton, and Claire Ballinger. 2011. Exercise for improving balance in older people. Cochrane Database of Systematic Reviews 11 (2011).

[15] Susan A Jackson and Herbert W Marsh. 1996. Development and validation of a scale to measure optimal experience: The Flow State Scale. fournal of sport and exercise psychology 18, 1 (1996), 17-35.

[16] Deborah Kendzierski and Kenneth J DeCarlo. 1991. Physical activity enjoyment scale: Two validation studies. fournal of Sport and Exercise Psychology 13, 1 (1991), $50-64$.

[17] Chiung-Ju Liu and Nancy K Latham. 2009. Progressive resistance strength training for improving physical function in older adults. Cochrane Database Syst Rev 3, 3 (2009).

[18] JA Garcia Marin, Elaine Lawrence, K Felix Navarro, and Christian Sax. 2011 Heuristic evaluation for interactive games within elderly users. In Proceedings of the 3rd International Conference on eHealth, Telemedicine, and Social Medicine (eTELEMEDâ̆̈́̈11). 130-133.
[19] Florian'Floyd' Mueller, Darren Edge, Frank Vetere, Martin R Gibbs, Stefan Agamanolis, Bert Bongers, and Jennifer G Sheridan. 2011. Designing sports: a framework for exertion games. In Proceedings of the SIGCHI Conference on Human Factors in Computing Systems. ACM, 2651-2660.

[20] Cornelius Neufeldt. 2009. Wii play with elderly people. Enhancing Interaction Spaces by Social Media for the Elderly 6, 3 (2009), 50-59.

[21] Australian Bureau of Statistics. 2017. Age composition and sex ratios - the past 20 years. Australian Demographic Statistics (3101.0), Dec 2016 (2017)

[22] Australian Bureau of Statistics. 2017. Underlying cause of death, selected causes by age at death, numbers and rates. Australian Demographic Statistics (3101.0), Dec 2016 Causes of Death (3303.0), Australia 2016 (2017).

[23] Davin Pavlas, Florian Jentsch, Eduardo Salas, Stephen M Fiore, and Valerie Sims. 2012. The play experience scale: development and validation of a measure of play. Human factors 54, 2 (2012), 214-225.

[24] Michael J Pavol, Eileen F Runtz, and Yi-Chung Pai. 2004. Young and older adults exhibit proactive and reactive adaptations to repeated slip exposure. The fournals of Gerontology Series A: Biological Sciences and Medical Sciences 59, 5 (2004), M494-M502.

[25] Zrinka Potocanac, Wouter Hoogkamer, Felipe P Carpes, Mirjam Pijnappels, Sabine MP Verschueren, and Jacques Duysens. 2014. Response inhibition during avoidance of virtual obstacles while walking. Gait \& posture 39, 1 (2014), 641-644.

[26] David Scott, Amanda L Stuart, Deborah Kay, Peter R Ebeling, Geoff Nicholson, and Kerrie M Sanders. 2014. Investigating the predictive ability of gait speed and quadriceps strength for incident falls in community-dwelling older women at high risk of fracture. Archives of gerontology and geriatrics 58, 3 (2014), 308-313.

[27] Catherine Sherrington, Julie C. Whitney, Stephen R. Lord, Robert D. Herbert, Robert G. Cumming, and Jacqueline C. T. Close. 2008. Effective Exercise for the Prevention of Falls: A Systematic Review and Meta-Analysis. Fournal of the American Geriatrics Society 56, 12 (2008), 2234-2243. https://doi.org/10.1111/j. 1532-5415.2008.02014.x

[28] Stephanie Studenski, S. Perera, E. Hile, V. Keller, J. Spadola-Bogard, and J. Garcia. 2010. Interactive video dance games for healthy older adults. The journal of nutrition, health \& aging 14, 10 (2010), 850-852.

[29] Kathleen Thomas and Meir Magal. 2014. How Does Physical Activity Impact Postural Stability. F Nov Physiother 4, 206 (2014), 2.

[30] Marielle Tschopp, Martin Karl Sattelmayer, and Roger Hilfiker. 2011. Is powe training or conventional resistance training better for function in elderly persons? A meta-analysis. Age and ageing (2011), 549-56.

[31] Dora TY Yau, Raymond CK Chung, and Marco YC Pang. 2013. Knee muscle strength and visual acuity are the most important modifiable predictors of fall in patients after hip fracture surgery: a prospective study. Calcified tissue international 92, 3 (2013), 287-295

[32] GAR Zijlstra, JCM Van Haastregt, J Th M Van Eijk, Erik van Rossum, Paul A Stalenhoef, and Gertrudis IJM Kempen. 2007. Prevalence and correlates of fear of falling, and associated avoidance of activity in the general population of community-living older people. Age and ageing 36, 3 (2007), 304-309. 